\title{
ANALYZING SPATIAL-PHYSICAL LAYOUT OF URBAN BAZARS: A WAY TO BRING BACK THE PUBLIC SPACES INSIDE MARKETPLACES WITH A CONSIDERATION FOR SAFETY ISSUES
}

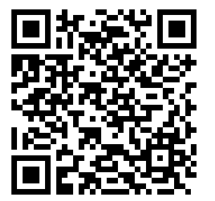

\author{
Muzaiana Naomi Khan ${ }^{1 凶(i D)}$, Saniya Tabassum ${ }^{2}$ 迥 (iD) \\ ${ }^{1}$ Senior Lecturer, Department of Architecture, Stamford University Bangladesh, Dhaka, \\ Bangladesh \\ ${ }^{2}$ Assistant Professor, Department of Architecture, Stamford University Bangladesh, Dhaka, \\ Bangladesh
}

DOI: https://doi.org/10.29121/granthaalayah.v9.i3.2021.3818

Article Type: Research Article

Article Citation: Muzaiana Naomi Khan, and Saniya Tabassum. (2021). ANALYZING SPATIAL-PHYSICAL LAYOUT OF URBAN BAZARS: A WAY TO BRING BACK THE PUBLIC SPACES INSIDE MARKETPLACES WITH A CONSIDERATION FOR SAFETY ISSUES. International Journal of Research GRANTHAALAYAH, 9(3), 321-337. https://doi.org/10.29121/granthaa layah.v9.i3.2021.3818

Received Date: 15 March 2021

Accepted Date: 31 March 2021

Keywords:

Analyzing

Bazars

Marketplaces

Consideration

Safety

\section{ABSTRACT}

The acceleration of diversified retail in urban streets and bazars, reachable from homes and work have become a common phenomenon in achieving an environmental, social, economic and sustainable neighborhood. Fostering social cohesion, such settlements encompass, groceries, confectionaries, soft drinks, magazines and newspapers, tobacco products, restaurants and cafes which help to build community. Local employment is also generated by such local trade points. Despite the popularity of street trading, the system of growth of such establishments remains chaotic and they lack public spaces within the market. This study analyses the dynamics of urban streets and bazar and social life at the local public space inside the market keeping in mind the current safety situation of the pandemic in three cases of Dhaka city and proposes possible opportunities to overcome the anarchy.

\section{INTRODUCTION}

Cities are results of the evolving conditions, culture, societies, politics, authority and economy of their birth and development. The business practices in a metropolitan area are as long established as the city itself. The social significance of understanding urban spatial structures demands a close examination of sustaining forces that frame urban communities inside the evolution of urbanization. (Mumford, 1970).

Market plays a critical part in urbanization in three aspects. The first of which is, how it drives the financial matters of the urban land price, as it is high value land use thus the spatial form of the surrounding areas and its uses. Second, it goes about being a significant appeal to influencing the pattern of urban development and space

(C) 2021 The Author(s). This is an open access article distributed under the terms of the Creative Commons Attribution License, which permits unrestricted use, distribution, and reproduction in any medium, provided the original author and source are credited. 
usage; and third, explicitly in developing countries, trading frequently is the primary type of work for migrants from rural areas showing up in the city. Its spatial form is in this way basic to the advancement of financial designs during the cycle of rapid urban development (Hossain, 2014).

The study of urban history shows that a number of elements have affected the advancement of old cities. The economy has consistently been quite possibly the main component of urban growth. In a traditional city, the marketplace has been a spot for the financial, social, political, cultural, and community space for the people (Moosavi, 2005). Bazar or marketplace is a place in a town where public sales are held, such as buying and selling of provisions, livestock, and other items. Some bazars are held daily which are called permanent markets while some are held once in a week or on specific dates such as festivals are called periodic markets. The structure of the market completely depends upon its whereabouts population, culture, ambience and geographic conditions. (Wikipedia, Marketplace)

A marketplace is one of the trademark factors of urban areas in various historical periods, which makes a city's social and economic life an indication of progress or backwardness. Usually, a marketplace is the focal point of protest or riots against the public authority or political framework and decides the destiny of the general public. Since the beginning of development and urbanization, marketplaces have existed in urban communities and have become a factor in the trading of culture between stages of civilizations. This situation implies that social orders create social trade by the immediate exchange of goods. (Masoudi Nejad, 2007).

However, activities near or inside many marketplaces have changed fundamentally for the outbreak of the pandemic COVID-19. In this paper, we illustrate how market places can revive as public spaces and reflect on their changing social dynamics, all while maintaining safety during this pandemic. Three case studies were taken in the city of Dhaka, the capital of Bangladesh, and a bazar and public activity layout are proposed keeping in mind the safety situation.

\subsection{OBJECTIVE}

The objective of the study is:

1) To understand the dynamics of how marketplaces function in the urban setting of Bangladesh in the light of historical development.

2) To identify the physical and spatial layout and configuration of the bazar in relation to the changing patterns of urban development keeping in mind the safety issues to be considered for the pandemic for the creation of public interactive space.

\subsection{METHODOLOGY}

The required data were collected from primary personal observation and some from secondary sources. Secondary data such as - various research relevant information, maps, photographs and data were collected from internet searches and previous research reports according to need. Internet sources include research papers, articles, online newspapers, reports and information published in the websites.

As a whole, despite the combination of all the analysis techniques, the data collection process followed a structured approach.

\subsection{LITERATURE REVIEW}

\subsubsection{EVOLUTION OF MARKET IN DHAKA}

Civilization was established in this delta land with the reference of the rivers, and the marketplaces were made right beside the river. These were the gateways for the city people to transfer products, river was the only way, and thus the marketplaces were established right beside that. In addition, the villagers' huts were built along the ghats [temporary transitional space]. (See Figure 1 and 2)

The historical backdrop of Dhaka as a city dates from four years prior, and in various periods of history, the city enlarged because of critical advancements in commerce and trade. Dhaka confronted six significant periods of financial and political change during its development. (Hossain. 2014) 


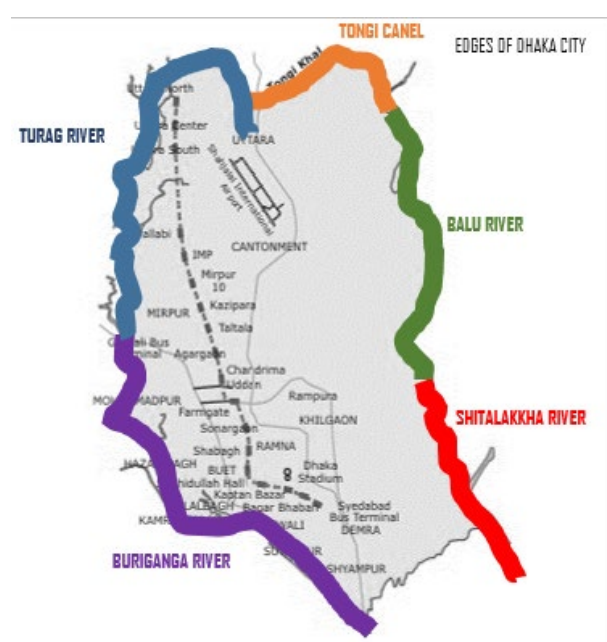

Figure 1: Dhaka surrounded by rivers

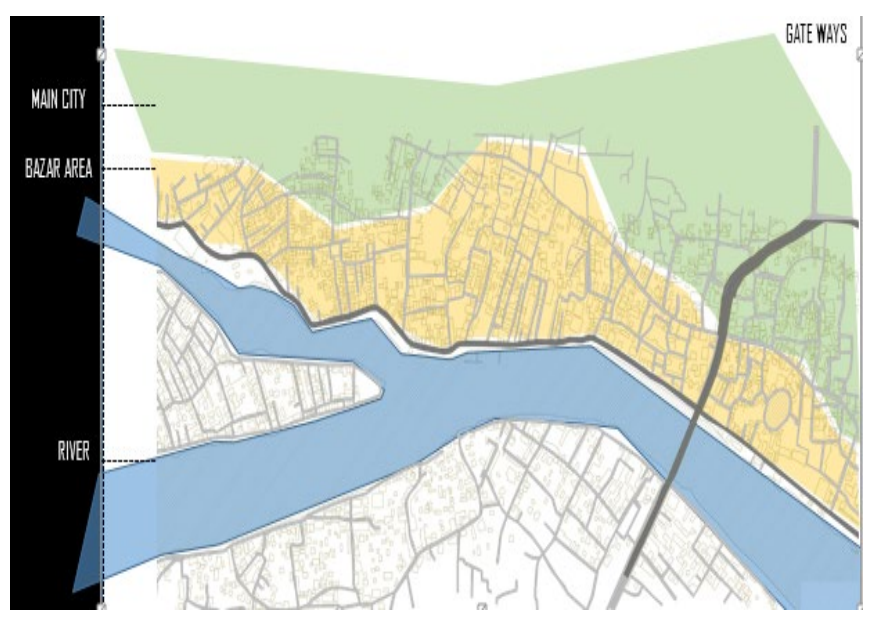

Figure 2: Growth of the city starting from the river

1) Pre-Mughal Hindu Period (Before 1608) - Before the Mughal era, Dhaka was a small Hindu trading center (Ahsan, 1991) situated between the Dhulai Khal and the Buriganga river. The Market center was near the Bangla Bazaar and Sadar Ghat and Victoria Park were the main business areas. (Dani, 1956). There was a spontaneous development of bazars in a linear pattern facing the streets along the residential areas. (Hossain, 2014)

2) Mughal Period (1608 - 1764) - During the era of Mughals, the needs of administration and defense combined with thriving business activities prompted Dhaka's development. From a suburban town, Dhaka turned into a city. (Khan and Atiquallah, 1965). The administrative center was located in the old fort area, which is now known as the central jail area. Close to the fort was the present Chawk Bazar area which grew as the main market center (Chowdhury and Faruqui, 1991). The Chawk Bazar being adjacent to the river Buriganga, gave the accommodation of water transport and being abundant in products, it rovided for both the privileged and lower-class neighborhoods. (Islam, 1996). (See Figure 3)

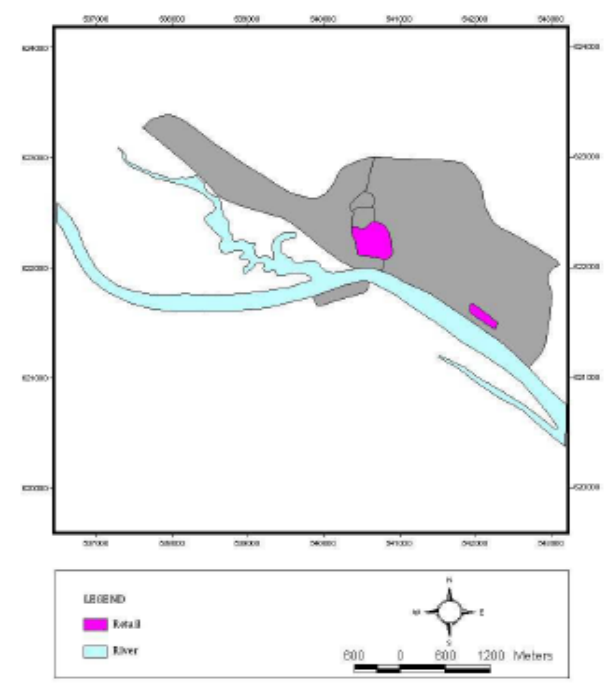

Source: Islam, 1996

Figure 3: Commercial land use of Dhaka in 1700.

3) The Rule of the East India Company (1764 - 1857) - Dhaka entered a sixty-year time of distress and political flimsiness when the Mughal Empire fell in 1707. In 1757, the capital was moved from Bengal to Calcutta. The change in regulation saw a decrease in exchange and business. When the spinning machine was invented, Dhaka's business activities further decreased. The political and administrative control of 
Dhaka was taken over by the East India Company in 1764 . The vast majority of the exchange and business exercises were completed in the fenced area of Chawk during this period. (Hossain, 2014)

4) British Colonization (1858 - 1947) - When the British came to power, Dhaka went through major transformation, which caused medieval Dhaka to turn into a modern city (Ahmed, 1986). The Chawk Bazar became a wholesale center from retail. To serve the British officials, new trading facilities were extended towards the north (Ahsan, 1991). Bengal was divided and Dhaka became the capital of the east Bengal in 1905 (Islam, 1991). (See Figure 4 and 5)

5) Pakistan Period (1947-1971) - Dhaka became the capital of East Pakistan in 1947. The city expanded when a vast number of Indian migrants emerged after partition causing a rapid growth in population. With the increase of urban expansion, administrative, commercial and residential needs increased causing further growth of the city. (Nilufar, 1997). There was mostly northern expansion. However, these expansions occurred spontaneously, without any proper planning or design. In 1956, the government formed the Dhaka Improvement Trust (DIT). It started planning the industrial district in Tejgaon, the first shopping center, Dhaka New Market, in Azimpur, staff housing in Motijheel, high class residential area in Dhanmandi and also several other high-class residential zones such as Gulshan (1964), Banani (1964) and Uttara (1965). (Hossain, 2014)

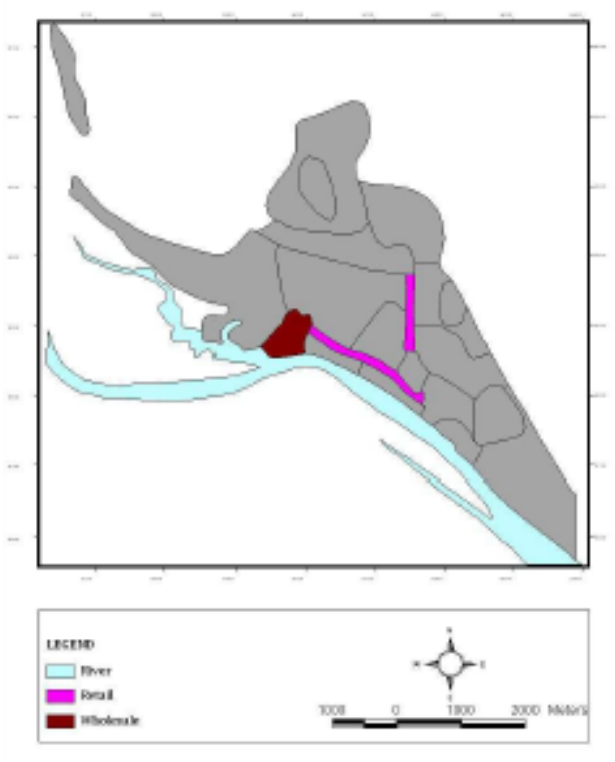

Figure 4: Commercial land use of Dhaka in 1910 Source: Islam, 1996

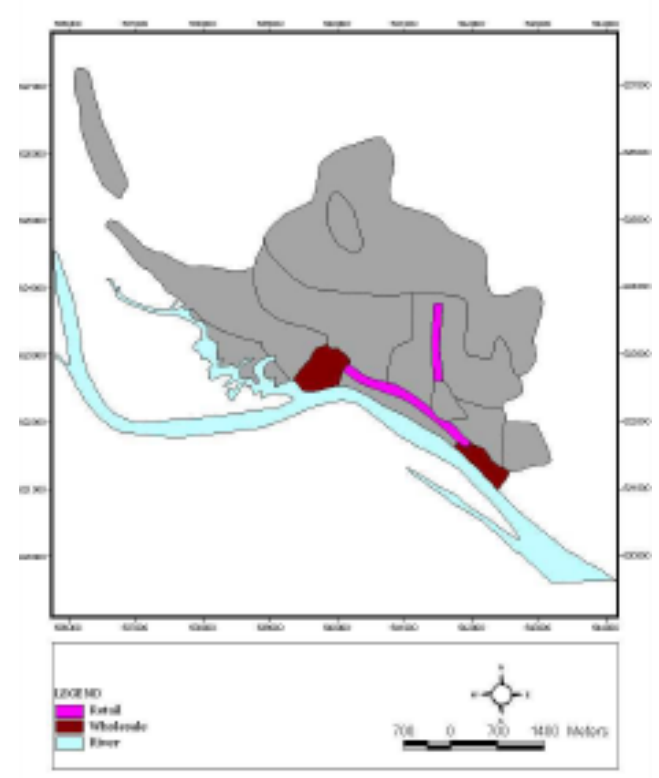

Figure 5: Commercial land use of Dhaka in 1945. Source: Islam, 1996

A number of new shopping centers were built to provide for these new residential areas. For example, Baitul Mukarram and Stadium shopping arcade in Gulistan business area, Gulshan North and Gulshan South shopping centers. The Motijheel-Gulistan area became the new commercial zone to cater for Dhaka's increasing commercial needs as the old business district became inadequate. The growth of New Market increased the commercial importance of Azimpur area. It also caused the development of other retail business around the area. The Gausia market, which started in 1965 was the first among them. However, the Chawk Bazar, Patuatoli and Sadar Ghat still serves as the business centers for the old part of the city (Ahsan, 1991). (See figure 6) 


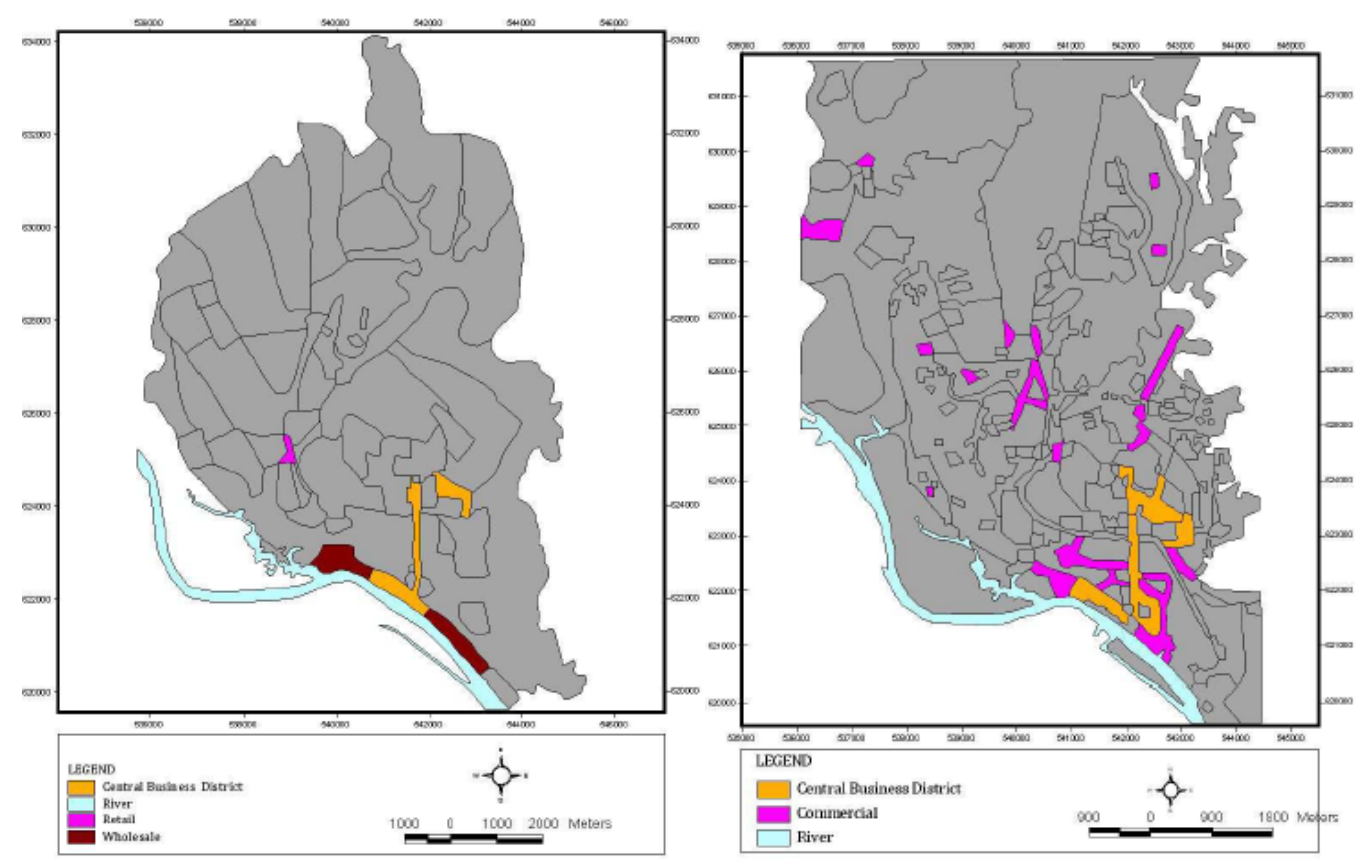

Figure 6: Commercial land use of Dhaka in 1962. Figure 7: Commercial land use of Dhaka in 1974. Source: Islam, 1996

Source: Jahangir, 1979

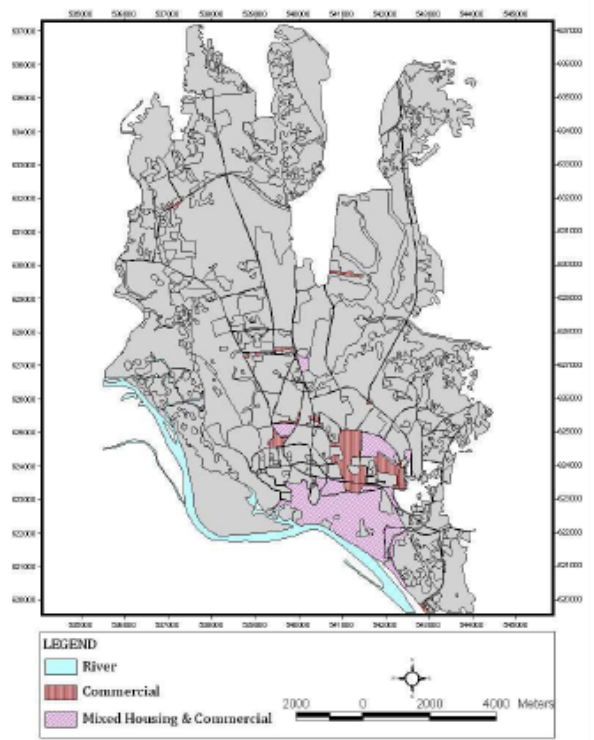

Figure 8: Commercial land use of Dhaka in 1984. Source: Strategic Transport Plan for Dhaka, 2005

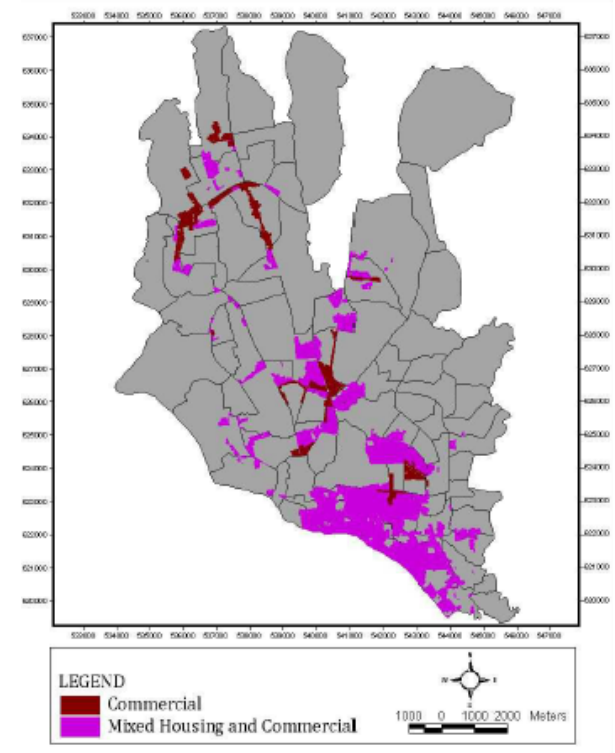

Figure 9: Commercial land use of Dhaka in 2004. Source: Gani Bangla Ltd, 2004

6) Bangladesh Period (1971 - until now) - After the liberation war in 1971, Dhaka became the capital of Bangladesh. It became the most influential and prominent hub for all of the nation's activities. The highlands towards the north, all soon became occupied with the sudden rise of population. No serious efforts had been taken to develop a planned city (Nilufar, 1997). The private sector stepped up when the government failed to cope with the unprecedented demand of the urban growth. A broad development of malls and shopping centers began to spread through private initiatives. Without any arranged drafting strategy, most of the retail centers started forming a linear pattern of development following the important routes through the upper- and middle-class residential areas. (Hossain, 2014). (See Figure 7, 8 and 9) 


\subsubsection{DHAKA AT PRESENT}

Dhaka, the capital of Bangladesh, is the commercial hub of the whole country. It has almost 1500 small and big markets. Products from all over the country enter Dhaka in some specific wholesale large markets and then go to the small markets in individual areas. Products also go from one city to another through Dhaka, as it is the center of the country.

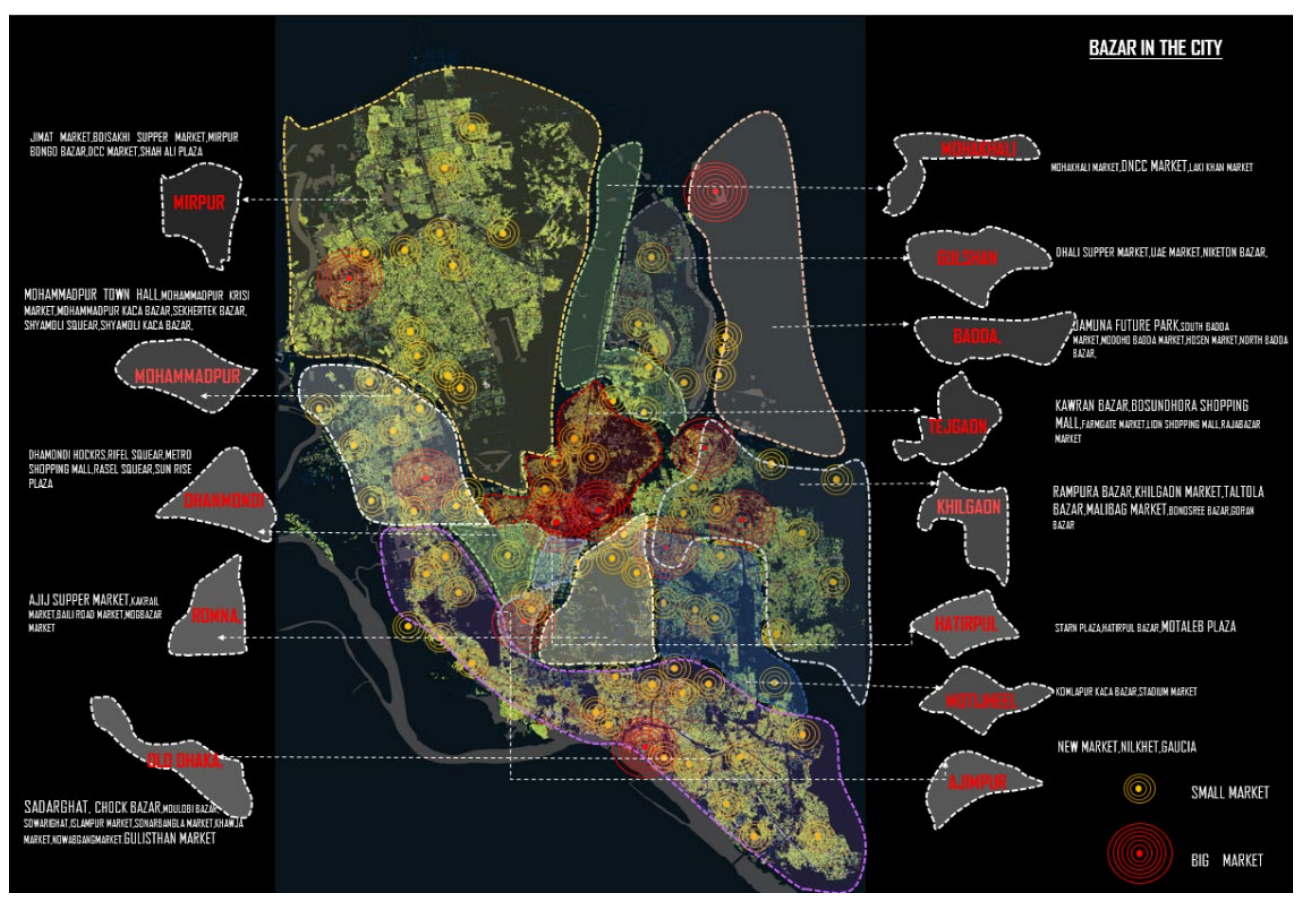

Figure 10: Big and small marketplaces in Dhaka city named area wise

\subsubsection{CONCEPT OF MARKETPLACE IN BANGLADESH}

Two types of Market- Dhaka New Market and Mohammadpur Krishi Market is discussed in this section, to identify the open bazar system of Dhaka City

\subsubsection{DHAKA NEW MARKET}

Dhaka New Market can be distinguished as the first planned marketplace for the city. It was built by the government in 1953. This complex can be perceived as a defining moment of change in the traditional marketplace morphology to the cutting-edge mall. English architect John High's idea of "open mall" for this complex was a popular practice of that period in Europe and North America (Hossain, 2000).

Major characteristic of this marketplace is its openness in planning and design. Shops of the inner and outer layers are adjusted along a wide covered hallway and open walkways in the middle of layers. These walkways are adequately wide to accommodate both shoppers and temporary vendors. About $55 \%$ of area of the complex is dedicated to circulation. (Islam and Adnan, 2011). From the very beginning of this complex, it is also one of the popular social gathering places for young generations. At first, this complex had a focal open court, which was later, in 1990, changed to a mosque at upper story and shops at ground floor. (See Figure 11 and 12) 


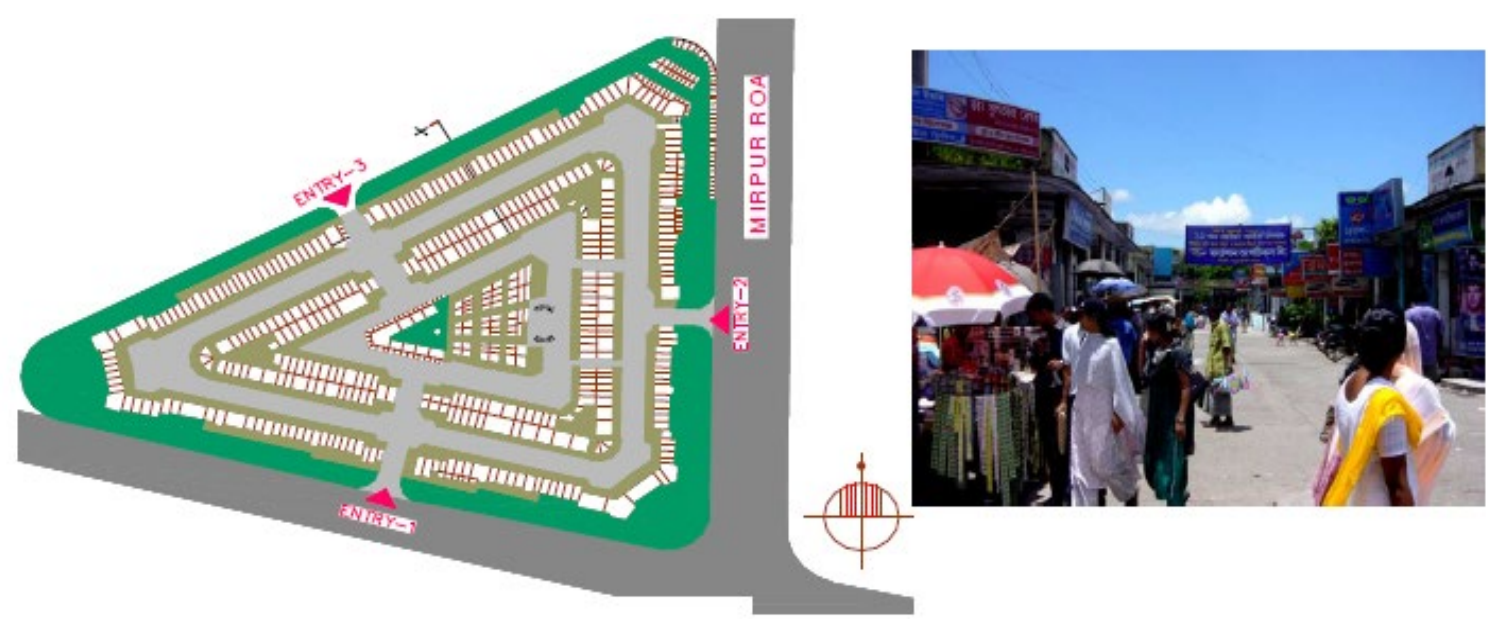

Figure 11: Plan of Dhaka New Market. $\quad$ Figure 12: Inside photograph of Dhaka New Market. Source: Islam and Adnan, 2011 Source: Islam and Adnan, 2011

\subsubsection{MOHAMMADPUR KRISHI MARKET}

Krishi Market, one of the key overwhelming places in Mohammadpur, was established in 1982 [with nearly 2 acres of land] by the government, under the ownership of the Directorate of Agriculture Ministry for Agricultural

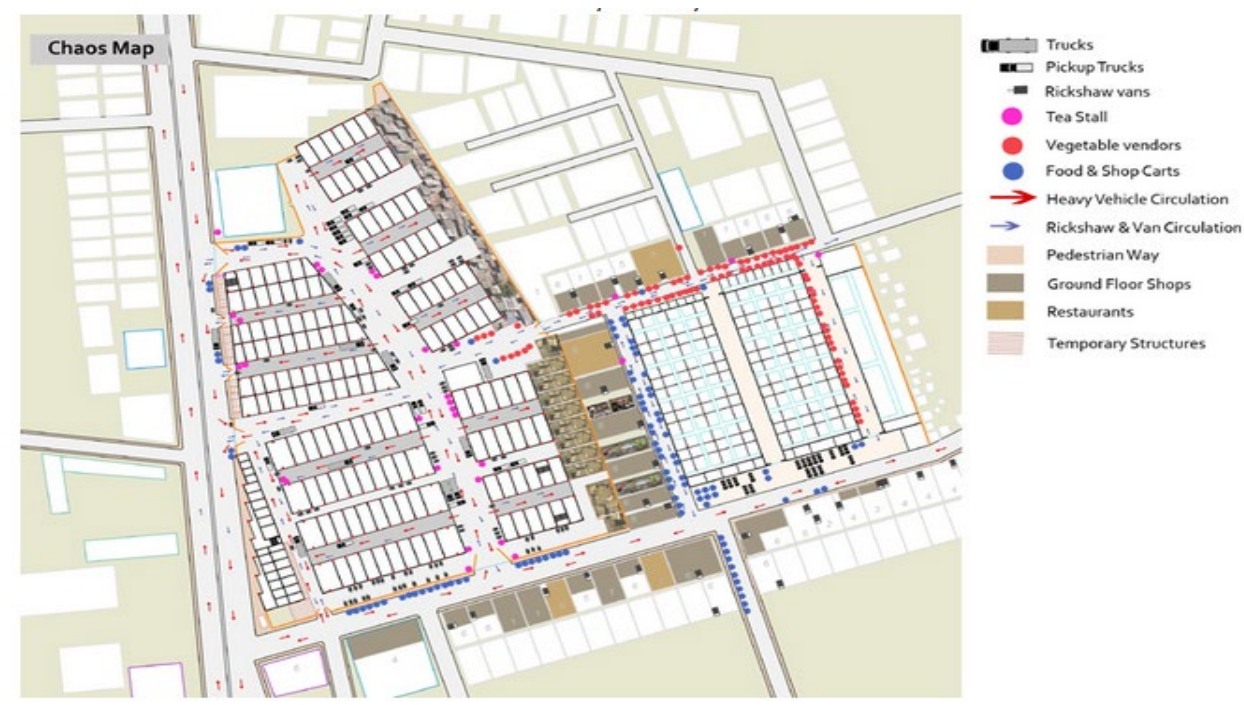

Figure 13: Plan of Mohammadpur Krishi Market.

Source: https://contextbd.com/remodeling-krishi-market-forming-community-square

Marketing of Bangladesh. They began the establishment with 400 shops in the market where clothing, groceries, jewelry, household items, stationery, vegetables, fish and meat were, and are still sold at reasonable prices. This Market acts as the storage hub of rice and lentils for the whole Mohammadpur area. At present, Dhaka North City Corporation operates the market. The entire market has two major parts. A major Aarot is in one side and a big Kacha Bazar and grocery shop on the other, in between are residential plots. The frontal portion of the Aarot covers

an area over 5 acres, with over 150 shops. The storage gives employment to more than 1400 workers and daily laborers. (Contextbd.com). (See Figure 13 and 14) 


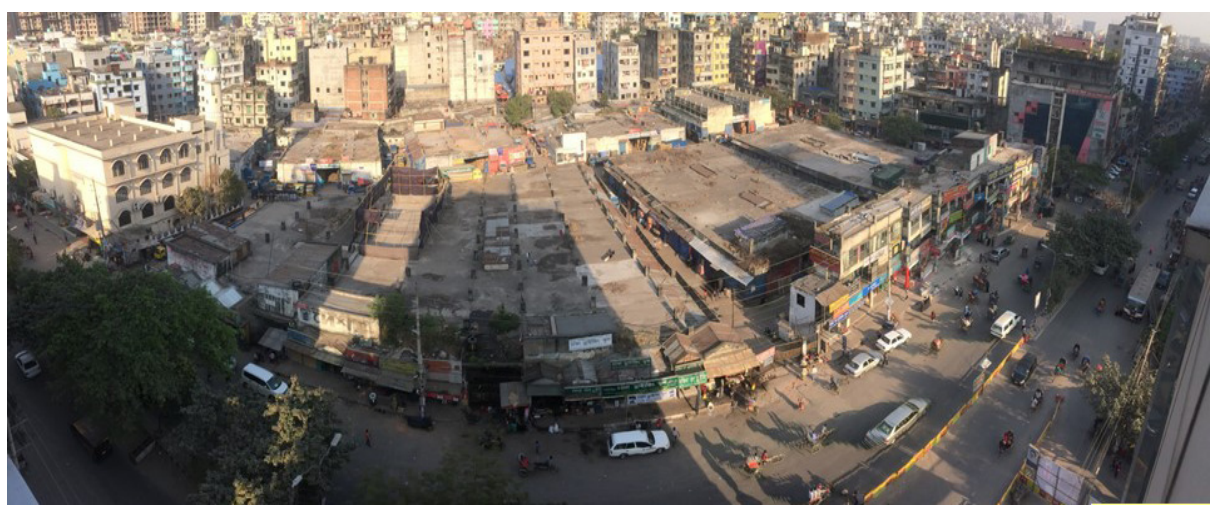

Figure 14: Arial view of Mohammadpur Krishi Market.

Source: https://contextbd.com/remodeling-krishi-market-forming-community-square-mohammadpur-aiub/

\subsubsection{OBSERVATION AND FINDINGS FROM THE CASE EXAMPLES}

Along with Dhaka New Market and Mohammadpur Krishi Market, some other popular and permanent bazars of Dhaka city were also observed; for example, Karwan Bazar, Rayer Bazar, Townhall Bazar, Gulshan DCC markets, Malibag Kitchen Market, Shantinagar Bazar, Uttara Sector 12 Bazar, etc. These markets are all well established and have been running for a long time now. There are many other temporary marketplaces or bazars too but both these categories are mostly unplanned and haphazard in terms of locational and hierarchical distribution. They are also overcrowded, compact and unhygienic. Due to the lack of planning guidelines, authority's concerns, owner's concerns and proper
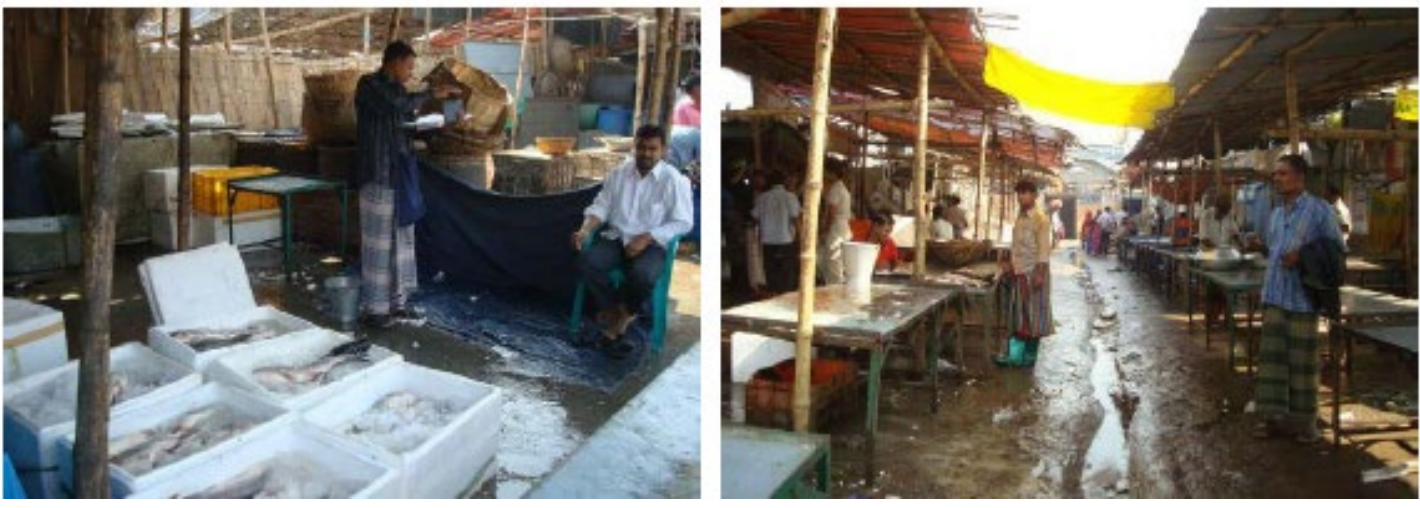

Figure 15: Unhygienic Condition of Jatrabri Fish Market

zoning in the bazars cause concerns in waste management, human resource management, trading, loading unloading system, fire safety system etc. (See Figure 15 and 16).

Other than Dhaka New Market, none of these bazars were planned to have any public space for people to interact with or even, when some space or courts were made, those were later taken up by shops.

There are many proposals by Dhaka City Corporation of redesigning and rethinking these bazars but these proposals only plan to accommodate more shops by making more permanent structures or by raising buildings in site. Government and concerned authorities have no concern for the public space inside the market place which can do a lot to improve the condition of the facilities of the current bazars.

Marketplaces are an instrument in the growth of the city because they are not only commercial spaces but also with its flexible spatial and temporary activities, they work as successful public spaces. It facilitates communication between people and products in relation to economic and cultural outlook. A public place reflects ourselves, our larger culture, our beliefs and values. When considering a public place, first we have to understand and conceptualize that they are thought of as a platform for the exchange of messages among diverse people. Public places include the city's streets and markets, sidewalks, parks, plazas, playgrounds and neighborhood spaces in residential areas to 
which all people have legal access. That's why public places are considered to be important in the social life of people and communities (Worpole, 2007).

The need to save our existing valuable public spaces is elevated considering urban population expansion. Therefore, it is very important to consider appropriate design guidelines for constructing a better bazar or marketplace.
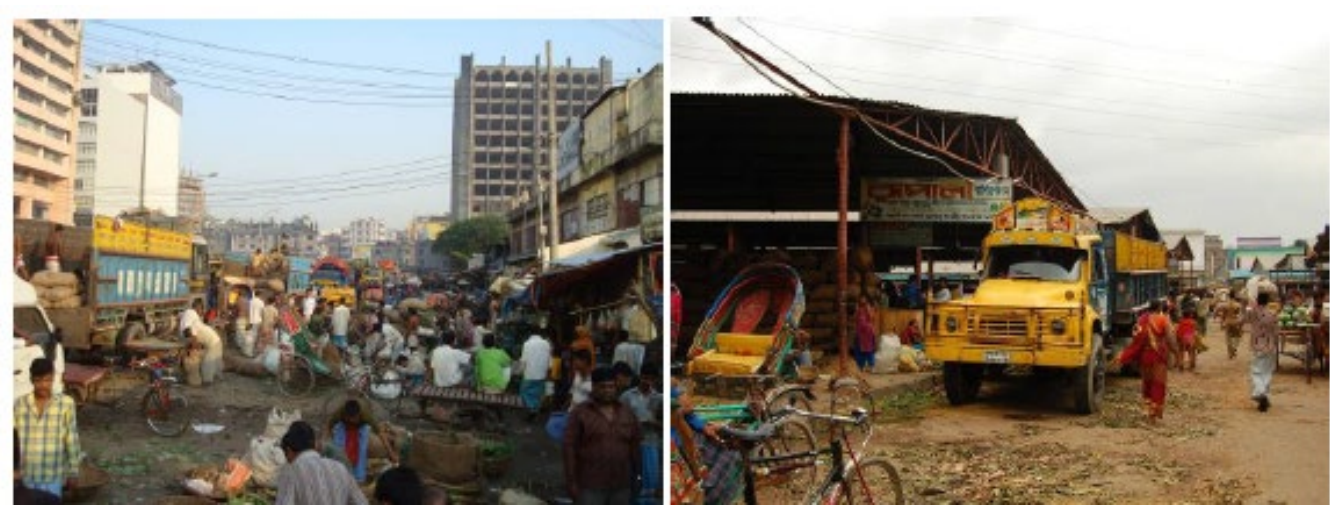

Figure 16: loading and unloading space of Karwan Bazar and of Jatrabri Bazar

\subsubsection{CURRENT BAZAR CONDITION DURING PANDEMIC COVID-19}

The new COVID-19 has constrained nations around the planet to receive measures, for example, flight boycotts, required lockdowns and social removing to keep the pandemic from spreading. Bangladesh had likewise stuck to this same pattern, prohibiting flights and closing down schools and universities yet workplaces actually stay open. In any case, for individuals in this densest nation on earth, social distancing is a difficult task.

TBS news reported on April 2020, that most of the bazars or marketplaces of the country are overcrowded even during this pandemic with utter disregard for social distancing guidelines. Moreover, many shopkeepers and sellers did not set up shops on the road outside the market, flouting the Dhaka Metropolitan Police's (DMP) instructions in this regard. As there is a high risk of coronavirus transmission from these areas, the Ministry of Land has directed local administrations of all districts on the $22^{\text {nd }}$ of April, 2020 to take steps to shift kitchen market sellers to set up shops on roads with at least 10 feet distance between each store. This will curb the Covid-19 pandemic by ensuring social distancing among shoppers, as they are the most crowded places in the city. Figure 17 shows a photo of Karwan Bazar during this pandemic with no consideration for social distancing.

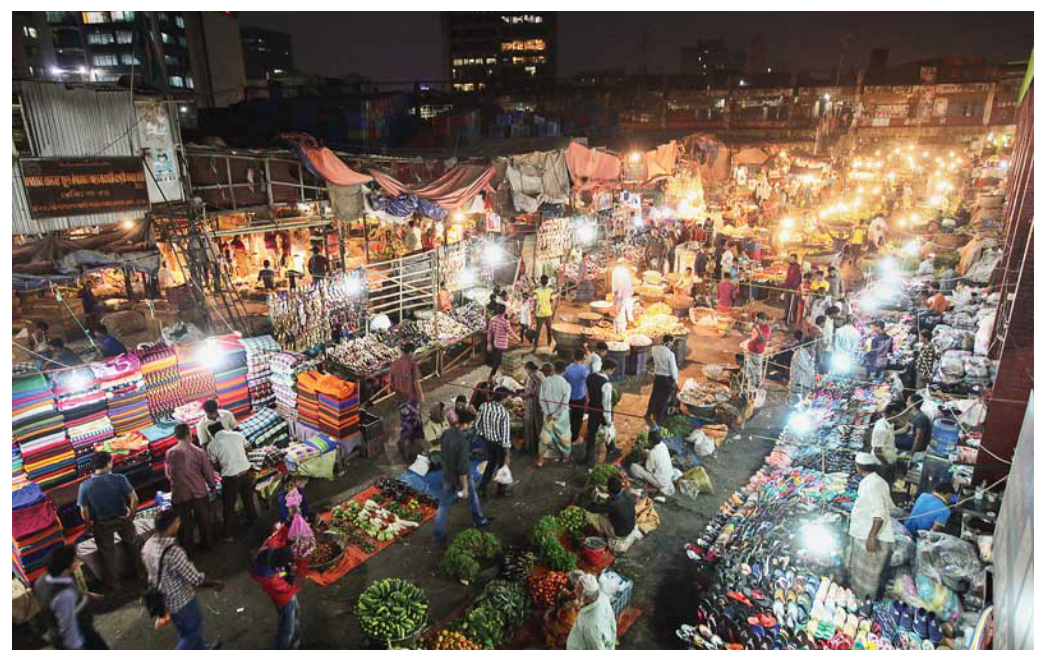

Figure 17: Photo of Karwan Bazar wholesale market in Dhaka, Bangladesh Source: https://www.dhakatribune.com/bangladesh/2020/04/27/coronavirus-kitchen-markets-to-relocate-to-open-spaces 
Analyzing Spatial-Physical Layout of Urban Bazars: A Way to Bring Back the Public Spaces Inside Marketplaces with A Consideration for Safety Issues

\subsubsection{SELECTION OF CASE STUDIES}

Three different sites have been selected in response to different kinds of needs and after studying all the situations and imbalances some proposals have been made from the three respective zones.

Study area 1: Bazar at South Banasree, Rampura, Dhaka (Area- 1.51 acres) - an urban street bazar which already exists in the name of Meradia Bazar at South Banasree, Rampura. (See figure 18). The government's plan is to uplift the bazar from the street and relocate the bazar to the site allocated in front of the primary road. However, the plan has no consideration for open public space in the bazar for the already compacted neighborhood.
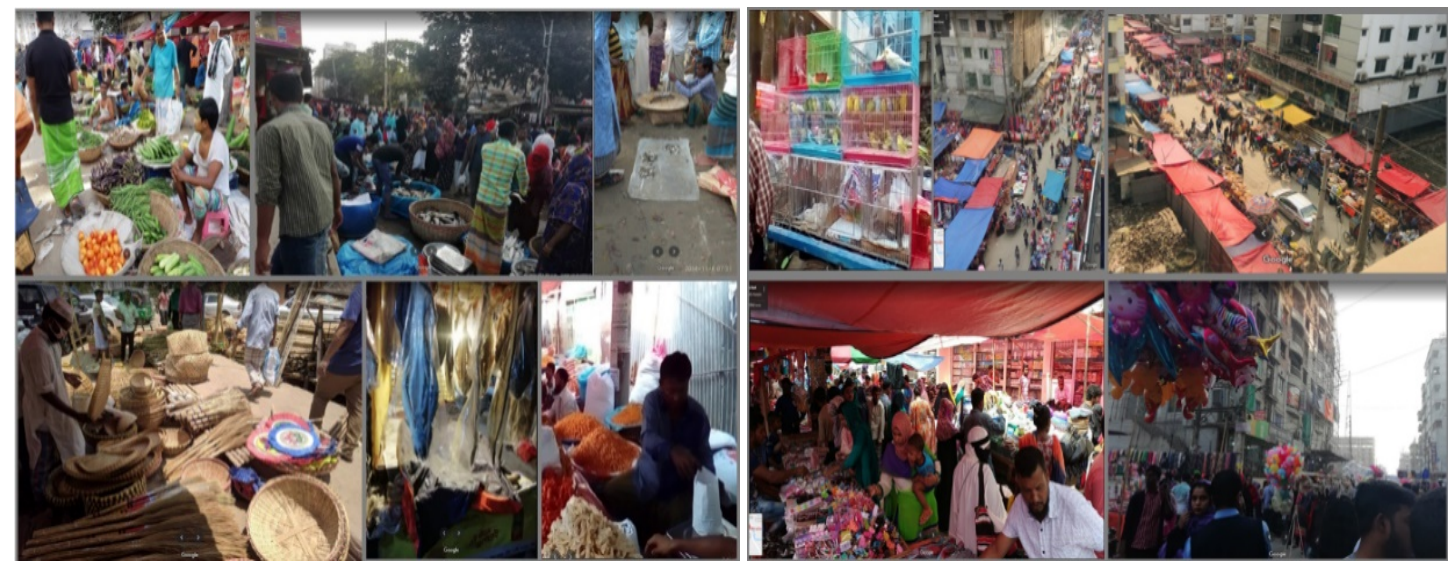

Figure 18: Photos of Study Area 1- Meradia Bazar at South Banasree, Rampura, Dhaka

Study Area 2: Bazar at Sector 12, Purbachal New Town, Dhaka (Area- 2.5 acres) - Purbachal developed due to the inadequacy of housing the large urban population of Dhaka. Some bazars already exist in Purbachal like Neela Market, Hordi Bazar, Ichapura Bazar, etc. (see Figure 19) but even in this new model town, the bazars are all unplanned and unhygienic with no consideration for public interaction in the market like the rest of the bazars of Dhaka.
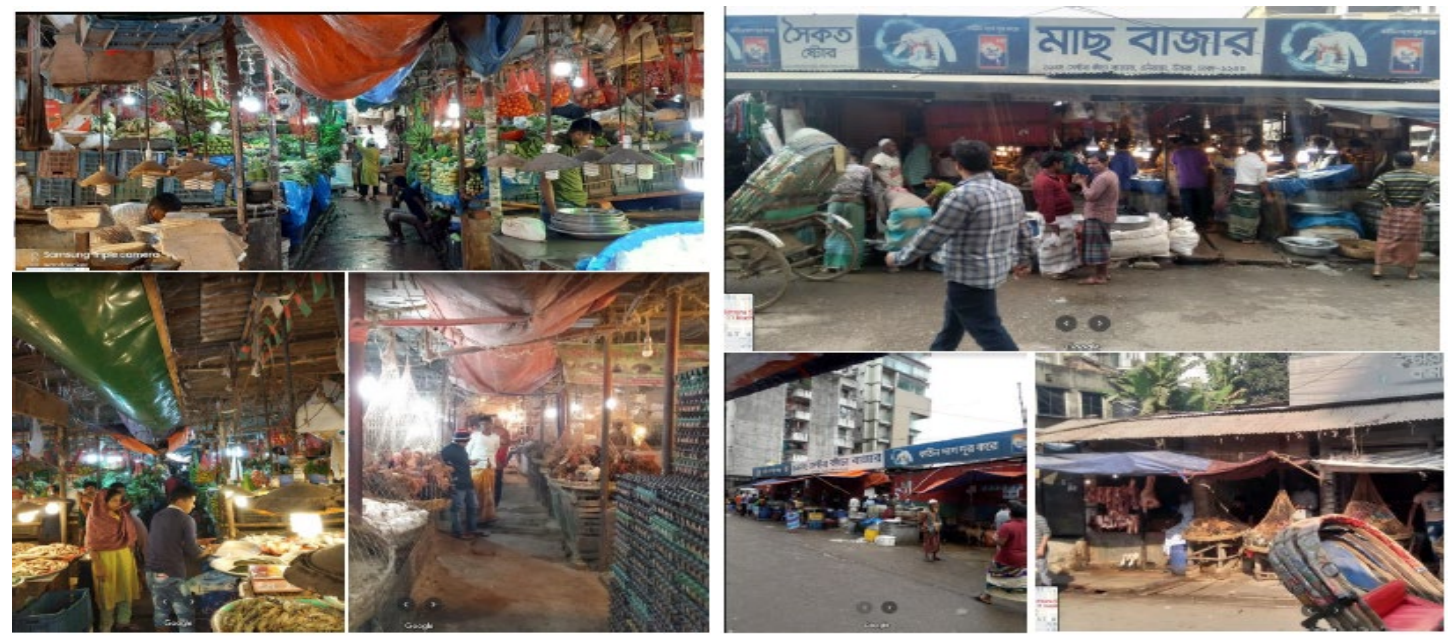

Figure 19: Photos of the already existing bazars of Purbachal

Study Area 3: Bazar at Uttara Sector 11, Uttara, Dhaka (Area- 1.79 acres) - A compact bazar to cater the neighborhood already exists in the site. However, the government's plan is to expand the market and make a tower building, more like a mall, by diminishing the bazar but what the neighborhood lacks is a public recreation zone and also these small retailers need to have a space to continue their business. 

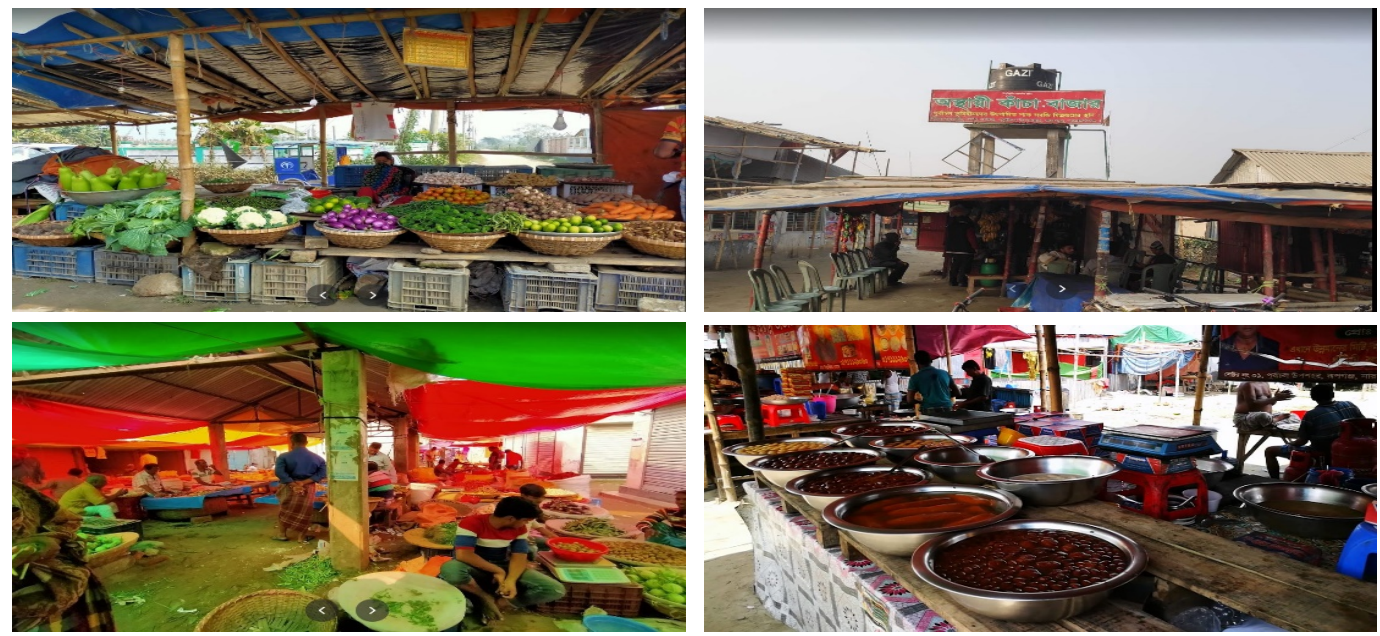

Figure 20: Photos of Study Area 3: Bazar at Uttara Sector 11, Uttara, Dhaka

\section{Study Area 1: Bazar at South Banasree, Rampura, Dhaka (Area- 1.51 acres)}

Rivers played a very important role in our country's trade and commerce from a very long time ago. For the ease of the transportation of supplies and goods, the bazar spaces were built mainly on the banks of rivers. As we can see, our study area also has a canal, which is connected with Hatirhjeel and Buriganga River. Over time, due to development and the building of roads, the water channel was pushed further and further away from the bazar.

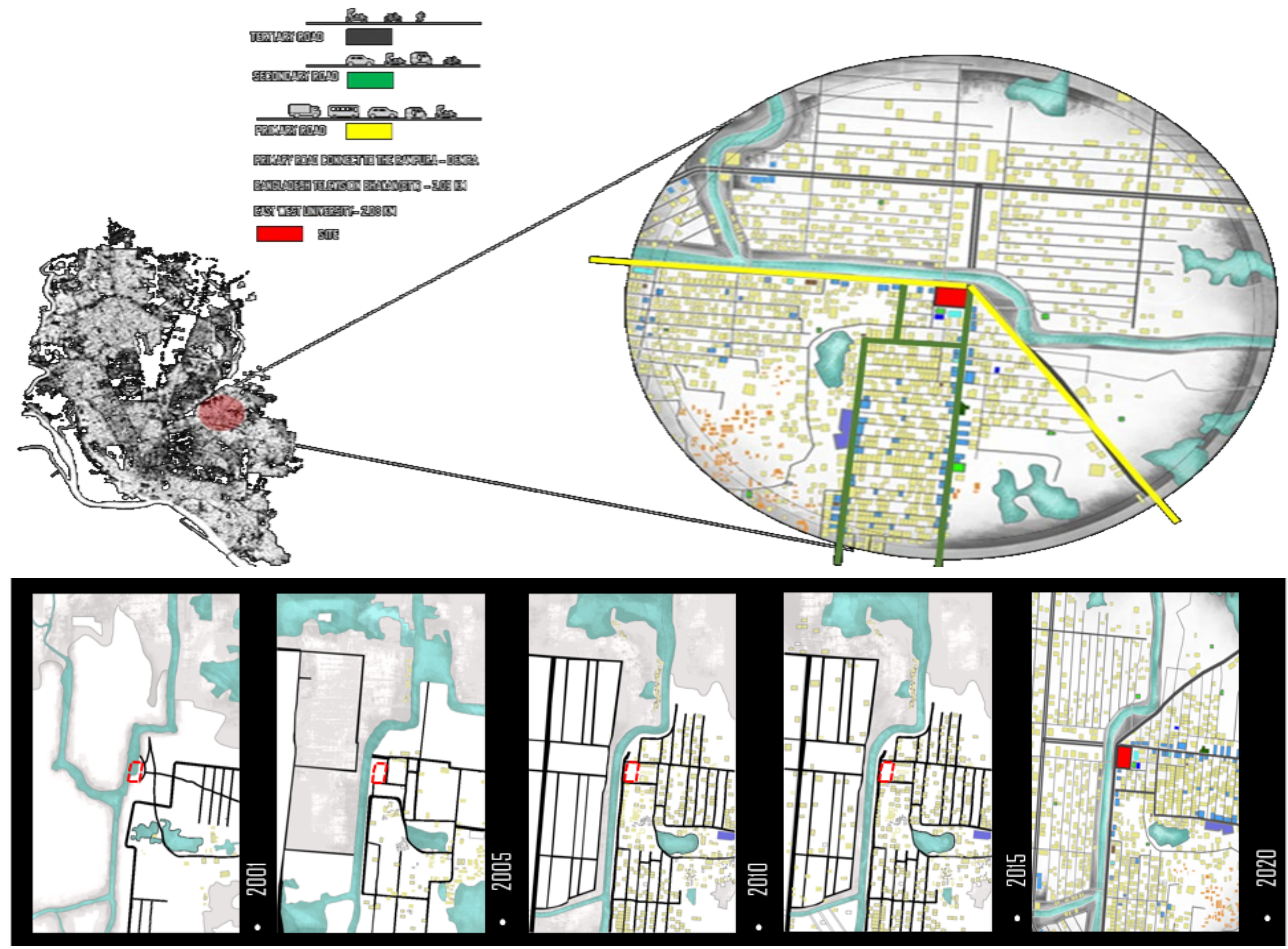

Figure 21: Study Area 1- Bazar at South Banasree, Rampura, Dhaka and different phases of development of the area with time

Site Analysis: Currently the site proposed for the street market relocation is dilapidated with 80' primary road on the north and secondary roads connects to the neighborhood through east and west. Both these streets contain the weekly bazar. The canal on the north also contains a temporary bamboo bridge for transfer of goods through the canal. Figure 21 shows the stages of development of the already compact neighborhood through time and figure 22 shows land use of the study area 1. 


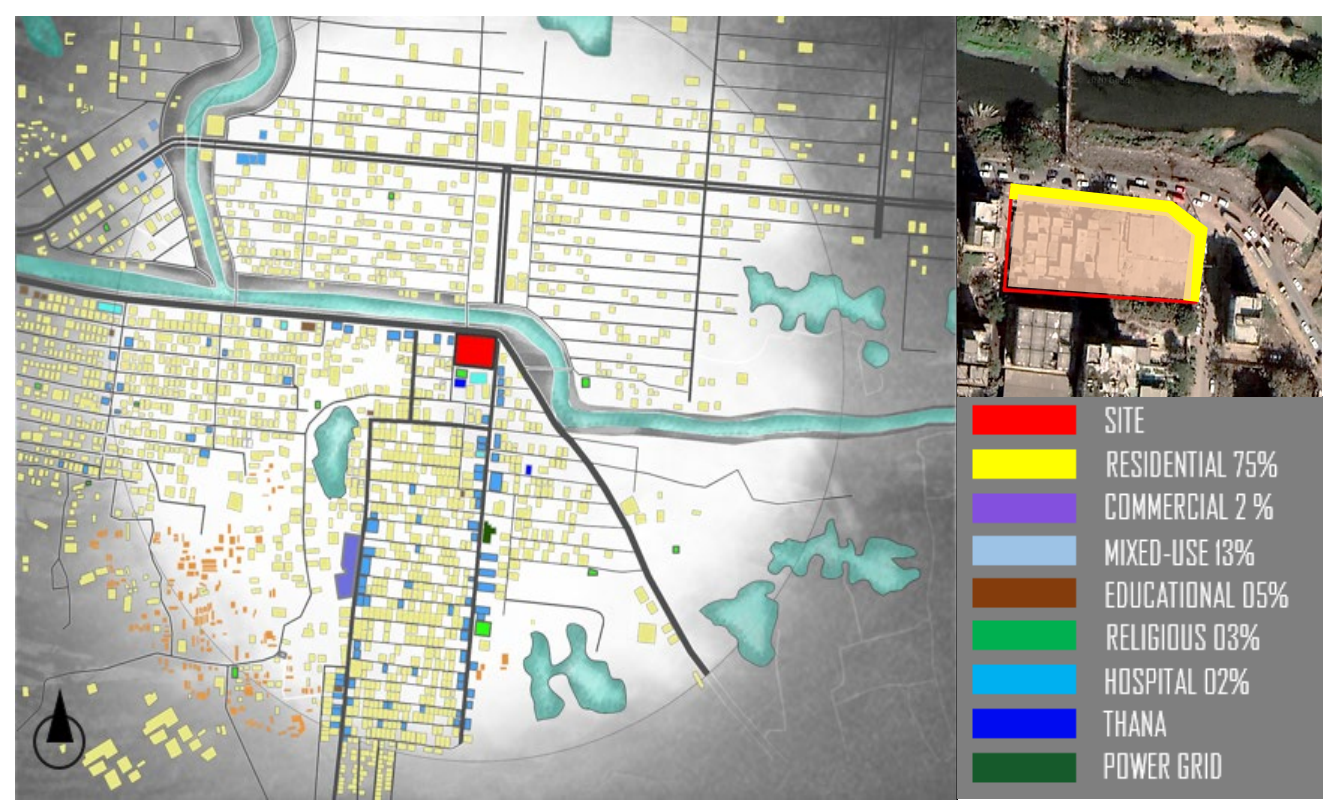

Figure 22: Land use map of Study Area 1- Bazar at South Banasree, Rampura, Dhaka.

Proposed Design Interventions: The main idea is to create a community hub to serve as a successful urban meeting place for the entire neighborhood. This requires providing pause space at the roadside and creating a permanent bridge for better communication through the canal and by providing space for street vendors using colorful tensile structures inside the allocated site taking inspiration from the layout of the weekly street market. Figure 23 shows the layout for the design considerations and sections of the indoor and outdoor market and figure 24 shows some $3 \mathrm{~d}$ perspective views.

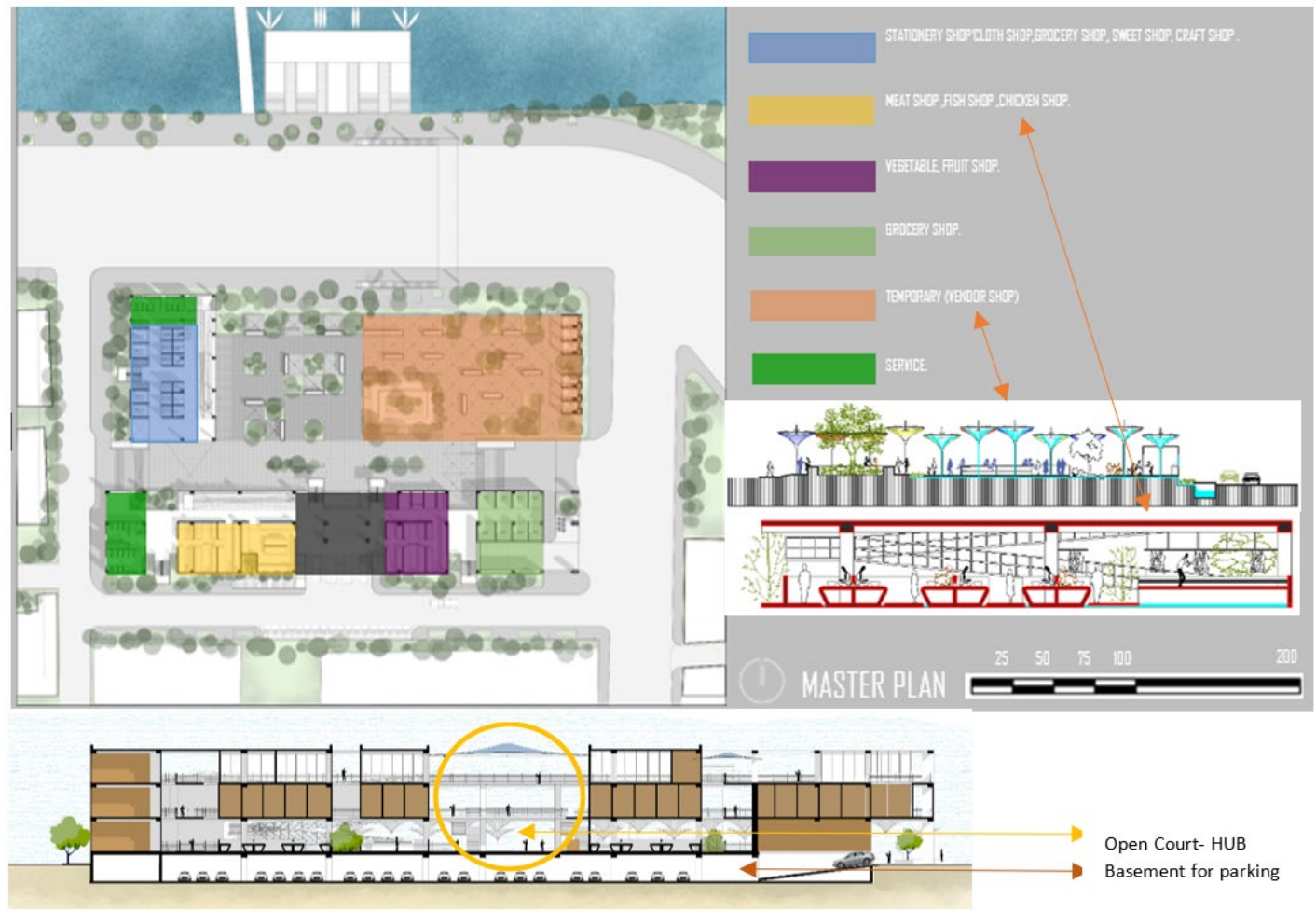

Figure 23: Proposed interventions for Meradia Bazar, South Banasree, Rampura 

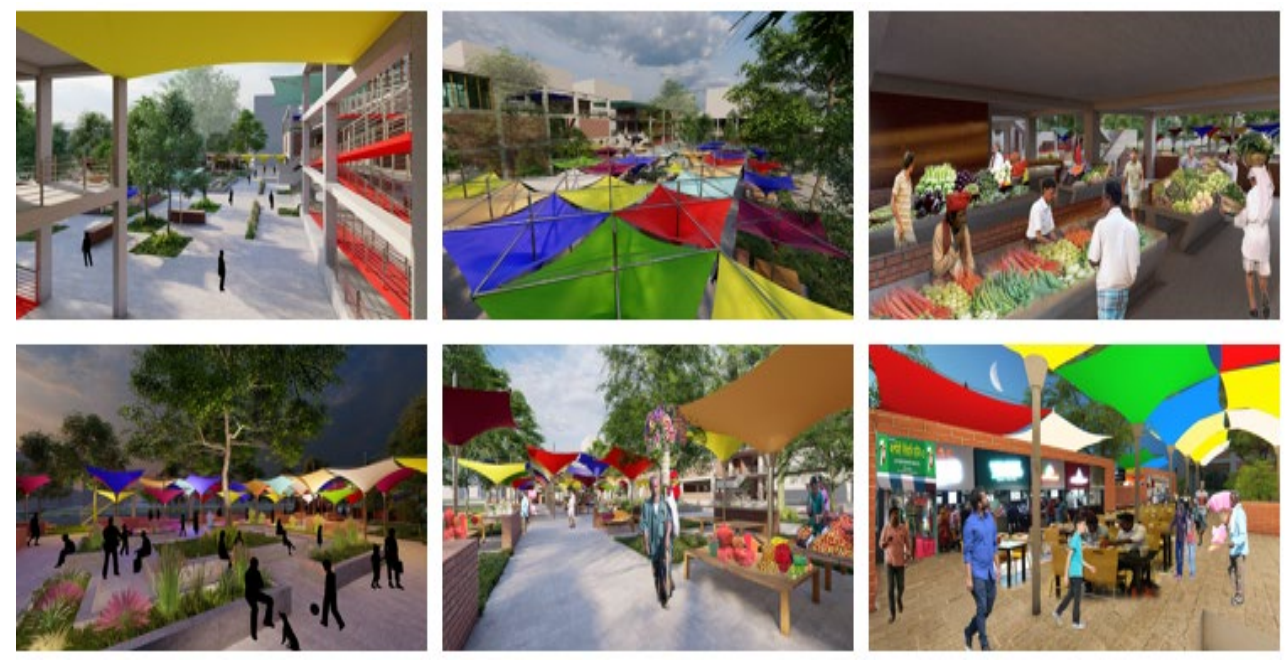

Figure 24: Proposed interventions for Meradia Bazar, South Banasree, Rampura

\section{Study Area 2: Bazar at Sector 12, Purbachal New Town, Dhaka (Area- 2.5 acres)}

As Dhaka has transformed into one of the busiest and densely populated cities, the already existing dwelling places for the large population are still quite insufficient. Therefore, the residential areas of Dhaka city are transforming into jam packed localities gradually thus causing an unhealthy environment. The pressure of increasing population in Dhaka can be decreased by expanding and developing the areas surrounding Dhaka in a planned manner and establishing permanent residential accommodation for the vast population. One such approach led to the development of "Purbachal". Purbachal New Town project is situated in between Rupganj Upazila of Narayanganj District and Kaliganj Upazila of Gazipur District in between river Balu and Sitalakhya at a distance of $16 \mathrm{~km}$ from zero point of Dhaka. The project implementation period was July 1995 to June 2014. The total area is 6,150 acres, which is divided into thirty sectors. There will be about 26,000 residential plots of different sizes and 62,000 apartments yet to be built. (Wikipedia, Purbachal Residential Model Town) (See figure 25)

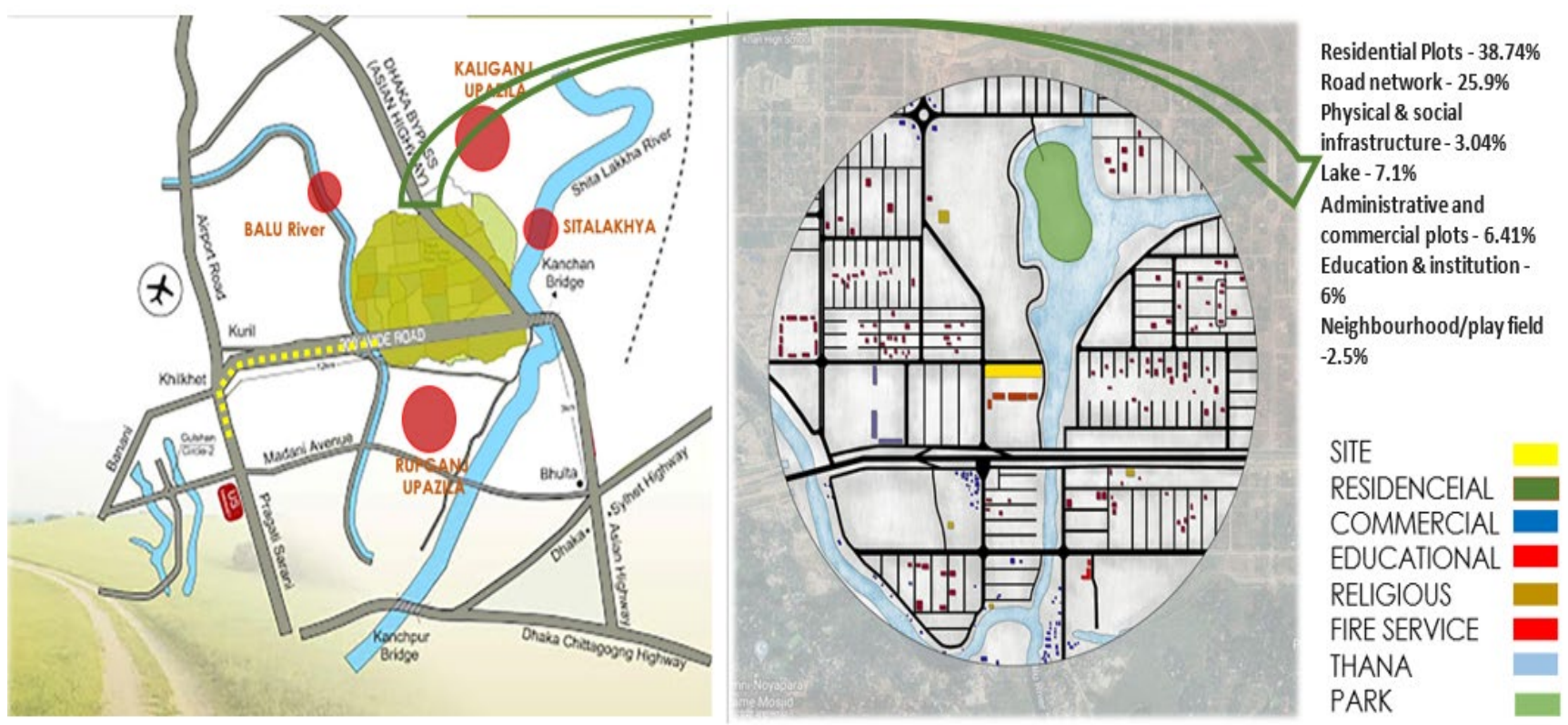

Figure 25: Land use map of Study Area 2: Bazar at Sector 12, Purbachal New Town

Site Analysis: The site proposed for bazar is surrounded by a residential neighborhood with an institutional zone at the north and fire service station at the south. A fifty feet wide road runs from the north to the west and a lake runs by the immediate east side of the site. 
Proposed Design Interventions: The core idea came from the lakeside walkways, which already exist, but demands a relaxation space nearby rather the hustle bustle of a bazar. To achieve this in this linear site, it is necessary to provide a green corridor for enhancing recreational facility and gatherings that the site demands. The location of the site in urban fabric is breathable, more openly. The thinking was improving commercial, recreational \& environmental conditions by respecting contextual characteristics of area. First, the bazar zone (wholesale \& retail) is organized in the linear pattern providing a lush green corridor in between the two wings. Tea stalls, food shops, sitting areas and provision for other vendors are located in between this playful green corridor, as it is not just a place for trading but also for communication, gathering and holding social characteristics. (See figure $26 \& 27$ )

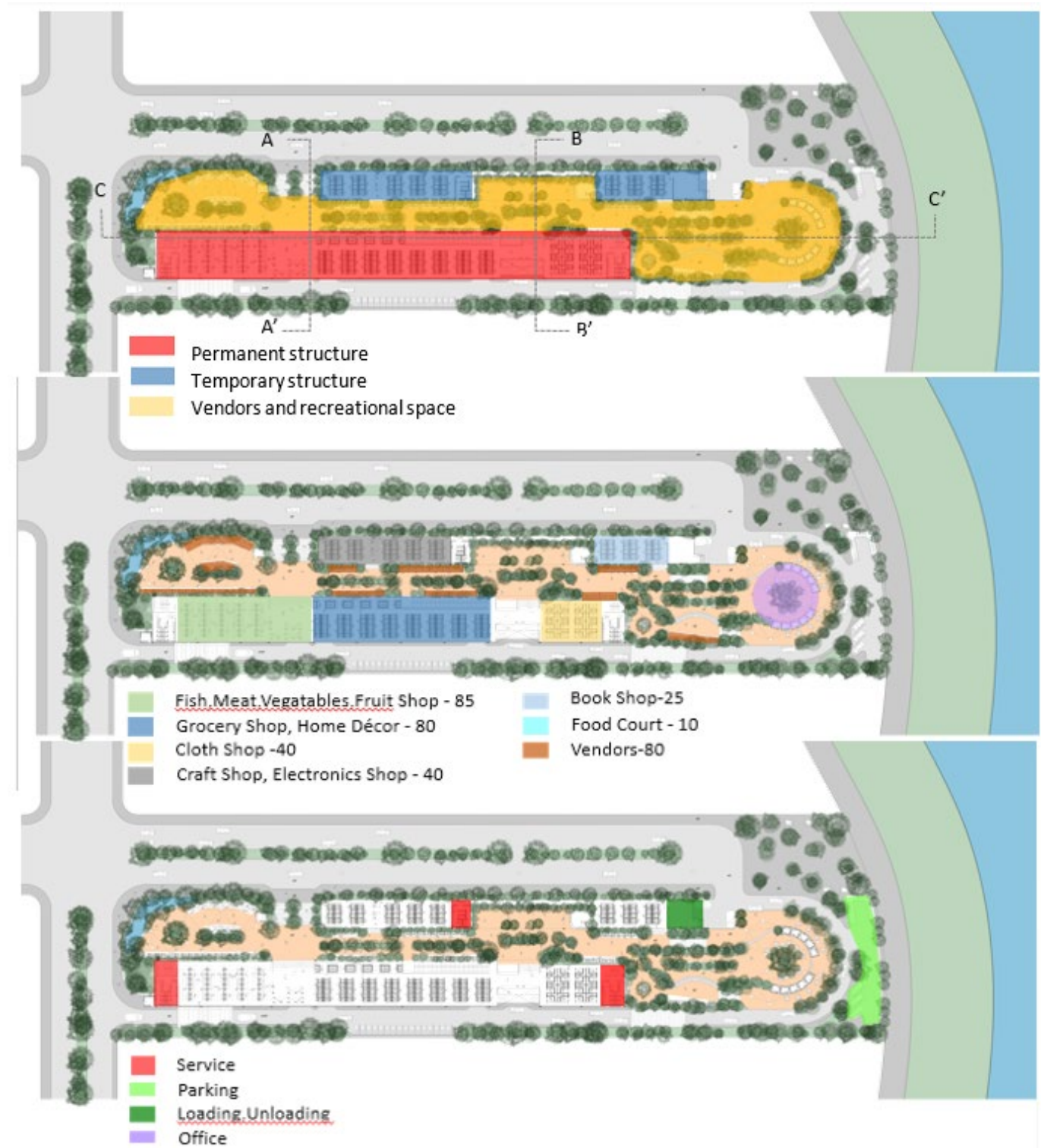

Figure 26: Proposed Interventions for Bazar At Sector 12, Purbachal New Town 

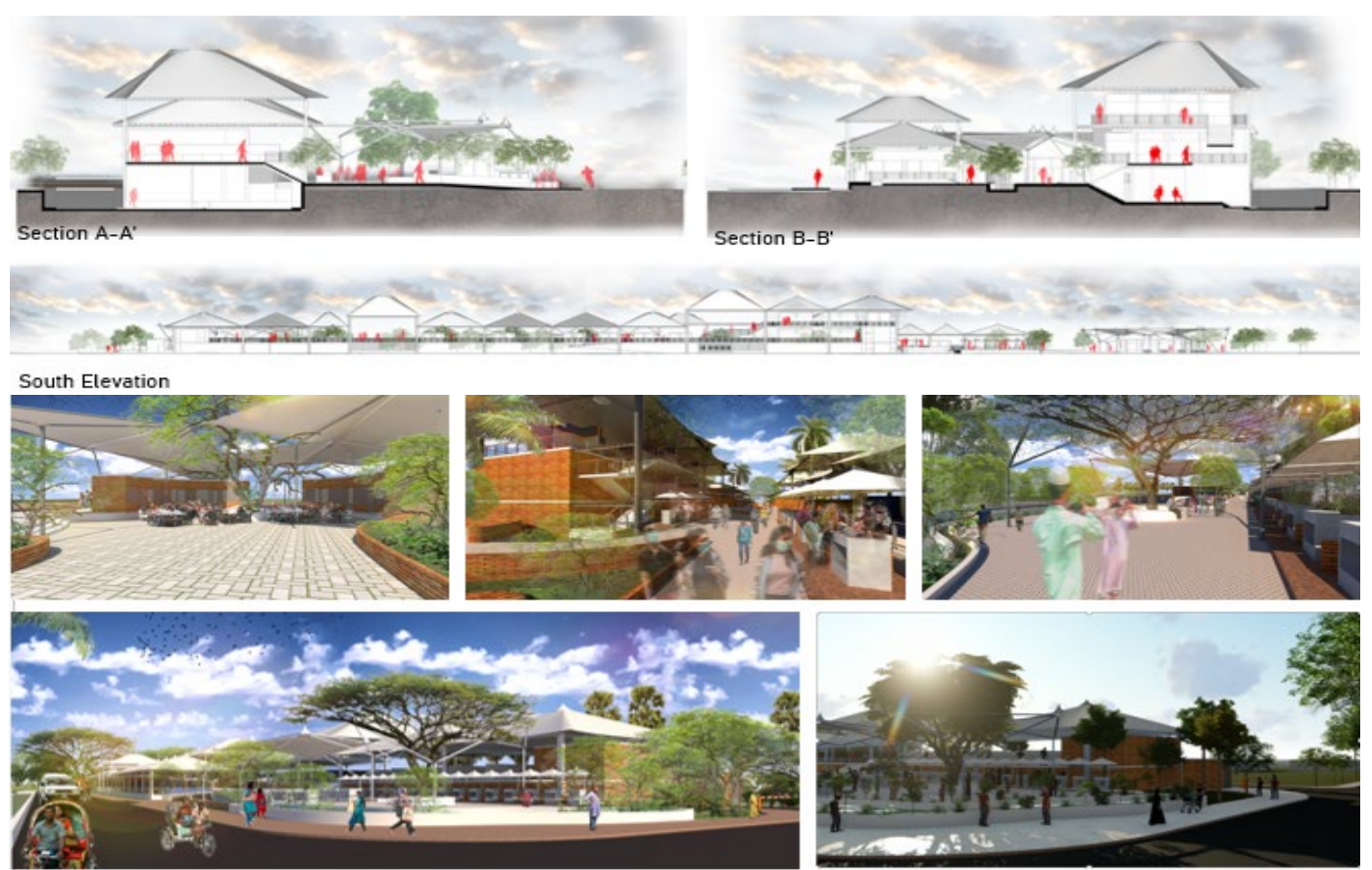

Figure 27: Proposed Interventions for Bazar at Sector 12, Purbachal New Town- section, elevation and 3d views

\section{Study Area 3: Bazar at Uttara Sector 11, Uttara, Dhaka (Area- 1.79 acres)}

Site Analysis: The site already contains a running bazar, which is in dire need of restoration. There is no proper entry to the bazar and it lacks parking facilities, thus, loading and unloading takes place in the road. The drainage system is poor and the bazar is made of temporary materials and in very detrimental condition. An 80 feet primary road runs from the south of the site and a 60 feet secondary road runs through the west into the neighborhood. (See Figure 28)
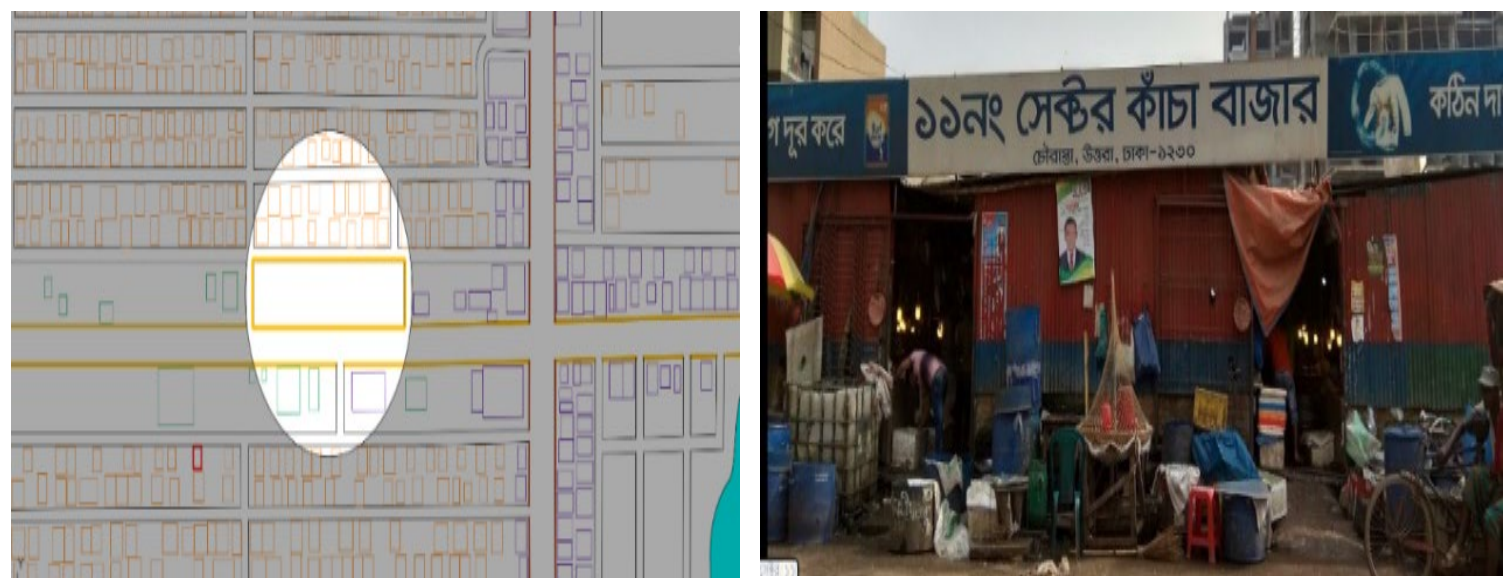

Figure 28: Map Study Area 3: Bazar at Uttara Sector 11, Uttara and photo of the entrance to the bazar

Design Interventions: The government proposal for this site is to make a multistoried building like a mall but this will put the livelihood of the small retailers and vendors at stake. Therefore, the idea for this design intervention is to create a shelter for all social class people that exist in the neighborhood, as well as the people who comprise of the existing bazar community, i.e., the wholesalers, retailers and vendors. (See Figure 29) 


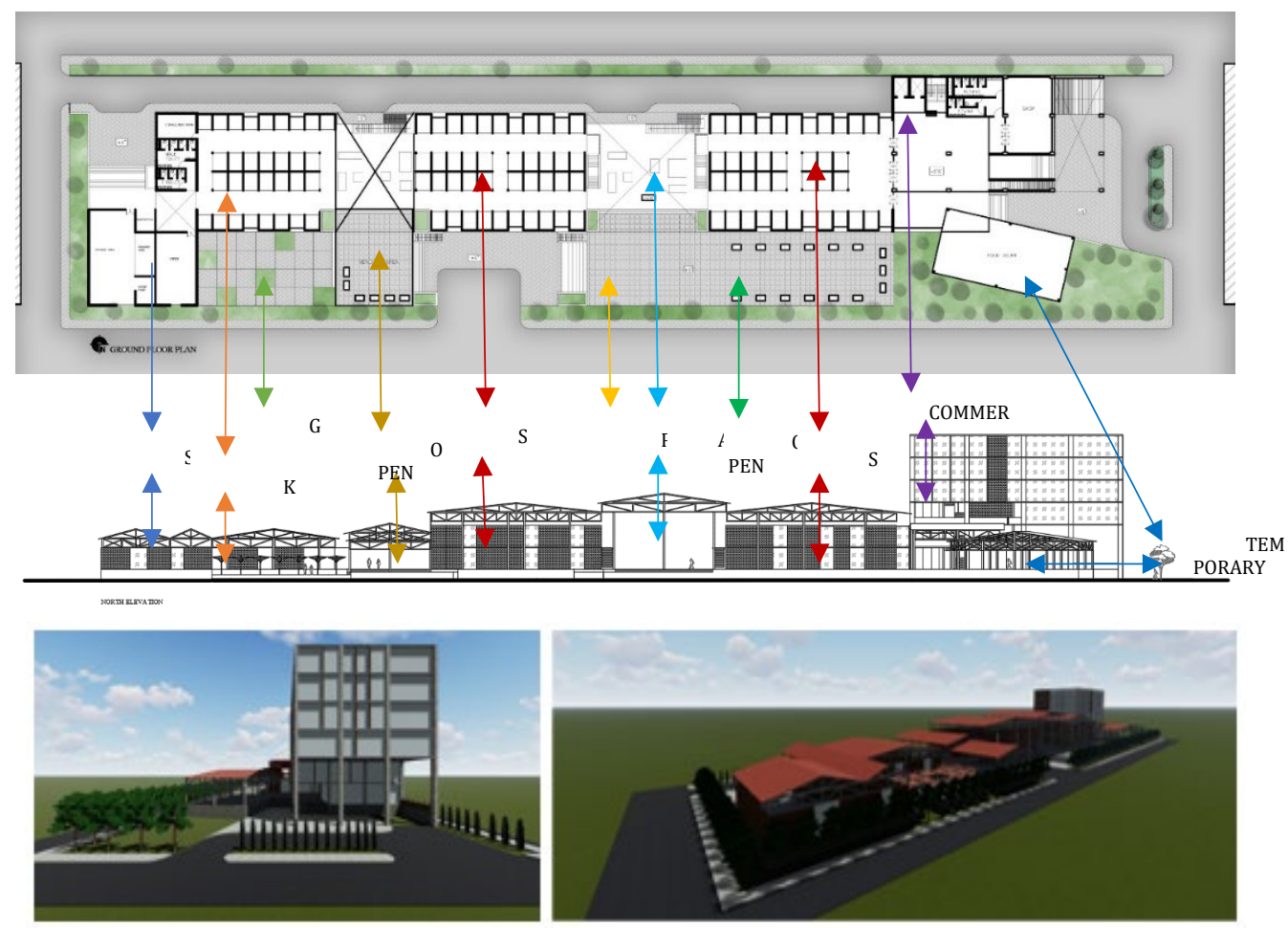

Figure 29: Proposed Intervention for Bazar at Uttara Sector 11, Uttara and photo of the entrance to the bazar

\section{OVERALL RECOMMENDATION AND CONCLUSION}

As the bazars of Dhaka city emerged as a public space from the very beginning, the recommendations for future bazar remains the same, i.e., to create not only a service space for buying and selling of products but also to revive the public gathering place as we have seen in the history. This can be done by incorporating a plaza or an outdoor open space like courtyard in between the bazar, or an indoor space like an atrium, or it can simply be a Bot Tola. It is a matter of planning and intension. However, few guidelines need to be followed in the creation of such bazar space: proper planning of wet and dry zones and public and semipublic activities, northsouth orientation of the built form for natural ventilation, wide circulation space and proper drainage system for maintaining health and hygiene situation, separate served and service entry and exit, proper plantation to reduce odour, etc.

All the three bazar's design proposals are accommodating to create a public gathering space even when the bazar or marketplace is closed. It is designed in a way that it serves as a community space for any time of the day or night. One with a courtyard type hub, one with a linear green corridor and another with plaza and atrium space, to preserve urban green and create urban civic space. The primary concern during designing of these proposals was social distancing. Other parameters included proper drop off for public, specific loading and unloading routes to the market, infrastructure such as, toilet facility, water connection, parking facilities, proper lighting and ventilation with odorless and hygienic conditions. The aim was to create a safe, comfortable, hygienic and most importantly sustainable market place integrating commercial, recreational and cultural activities.

\section{SOURCES OF FUNDING}

This research received no specific grant from any funding agency in the public, commercial, or not-for-profit sectors.

\section{CONFLICT OF INTEREST}

The author have declared that no competing interests exist. 


\section{ACKNOWLEDGMENT}

First and foremost, we would like to thank the Almighty. Then we would like to extend our gratitude to the students of Batch 64 of Stamford University Bangladesh, Zulkar Nien Miraj, Al Baizid Lalan, Shuvra Deb Halder, Md. Jewel Chokdar, Md. Abdullah Al Mamun, Ashis Barua, Masudur Rahman and Mehedi Sarjin Sifat to carry out the survey and for helping create the drawings and 3D modelling. And last but not the least Ar. Shahnaz Masud.

\section{REFERENCES}

[1] Ahmed, S.; (1986); Dacca: A Study in Urban History and its Development; London Centre for South Asian Studies, School of Oriental and African Studies.

[2] Ahsan R.M.; (1991); Changing Pattern of the Commercial Area of Dhaka City; Dhaka Past, Present \& Future; in Ahmed. S. U. (Ed.); The Asiatic Society of Bangladesh.

[3] Chowdhury, A.M., and Faruqui, S.; (1991); "Physical Growth of Dhaka", In Sharif Uddin Ahmed (ed.); Dhaka Past Present Future; The Asiatic Society Of Bangladesh.

[4] Dani, A.H.; (1956); Dacca: A Record of its Changing Fortune. Dhaka: Asiatic Press.

[5] Gani Bangla (pvt) Limited (GBL), (2004), "Interim Report of Detail Area Planning of Dhaka Metropolitan Area". An unpublished report submitted to RAJUK, Dhaka.

[6] Hossain, N; (2014), History of Commercial Development in Dhaka and the Spatial Significance of Spontaneous Retail Growth, IOSR Journal Of Humanities And Social Science (IOSR-JHSS) Volume 19, Issue 11, Ver. VII (Nov. 2014), PP 66-73.

[7] Hossain N. (2000), The Socio-Spatial Structure of Spontaneous Retail Development in Dhaka City, Ph.D. Thesis, Department of Architecture, University of London, pp 132-133.

[8] Islam, M.N.; (1991); The Political Role of Dhaka.

[9] Islam, N.; (1996); Dhaka from city to megacity; Urban Studies Program; Department of Geography; University of Dhaka.

[10] Islam, I, and Adnan, M.S.G.; (2019); Commercial Land Use in Dhaka: An Analysis of Trend and Pattern, 400 Years of Capital Dhaka and Beyon, Volume III: Urbanization and Urban Development.

[11] Jahangir, M. H. (1979); Development costs in alternative residential land use: a study of public housing in Dacca, Unpublished MURP Thesis, Department of Urban and Regional Planning, BUET, Dhaka.

[12] Khan, Atiquallah; (1965); In Sharif Uddin Ahmed (ed.); Dhaka Past Present Future; The Asiatic Society Of Bangladesh.

[13] Masoudi Nejad, Reza, (2007); Social and Commercial: Comparative Study of Spatial Role of Iranian in the Historical Cities in Different Socio-economical Context. University College London, pp 187-200.

[14] Moosavi, M.S., (2005); Bazaar and its role in the development of Iranian traditional cities. Conf. Proc. 2005 IRCICA int. Conf. Islamic Archeology.

[15] Mumford, L.; (1970); The Culture of Cities; Harcourt Brace Jovanovich, Inc.; New York.

[16] Nilufar, F., (1997) "The Spatial and Social Structuring of Local Areas in Dhaka City - A Morphological Study of the Urban Grid with Reference to Neighbourhood Character within Naturally-grown Areas." Unpublished Doctoral Thesis; Unit for Advanced Architectural Studies; The Bartlett School of Graduate Studies, University College London, University of London.

[17] STP, (2005), The Strategic Transport Plan for Dhaka (final report), The Louis Berger, Group Inc, Bangladesh Consultant Ltd.

[18] Worpole, Ken and Knox, Katharine. (2007). "The social value of public spaces". Joseph Rowntree Foundation

[19] www.contextbd.com/remodeling-krishi-market-forming-community-square-mohammadpur-aiub/

[20] www.dhakatribune.com/bangladesh/2020/04/27/coronavirus-kitchen-markets-to-relocate-to-openspaces

[21] https://en.wikipedia.org/wiki/Marketplace

[22] https://en.wikipedia.org/wiki/Purbachal_Residential_Model_Town

[23] www.tbsnews.net/markets/kitchen-market-sellers-flout-social-distancing-rules-dhaka-74161. 